\title{
Enhanced Recovery Pathway for Urgent Colectomy
}

\author{
Didier Roulin • Catherine Blanc • \\ Mirza Muradbegovic • Dieter Hahnloser • \\ Nicolas Demartines • Martin Hübner
}

Published online: 26 March 2014

(C) Société Internationale de Chirurgie 2014

\begin{abstract}
Background Enhanced recovery protocols have been proven to decrease complications and hospital stay following elective colorectal surgery. However, these principles have not yet been reported for urgent surgery procedures. We aimed to assess our initial experience with urgent colectomies performed within an established enhanced recovery pathway.

Methods In a prospective cohort study, all patients undergoing colonic resection between April 2012 and March 2013 were treated according to a standardized enhanced recovery protocol. Urgent surgeries were compared with the elective procedures with regards to baseline characteristics, compliance with enhanced recovery items, and clinical outcome.

Results Patients $(N=28)$ requiring urgent colonic resection were included and compared with patients undergoing elective colectomy $(N=63)$. Overall compliance with the protocol was $57 \%$ for the urgent compared with $77 \%$ for the elective procedures $(p=0.006)$. The pre-operative compliance was 64 versus $96 \%(p<0.001)$, the intra-operative compliance was 77 versus $86 \%$ ( $p=0.145)$, and the post-operative compliance was 49 versus $67 \%(p=0.015)$, for the urgent and elective
\end{abstract}

D. Roulin · M. Muradbegovic $\cdot$ D. Hahnloser .

N. Demartines $(\square) \cdot$ M. Hübner

Department of Visceral Surgery, University Hospital of

Lausanne (CHUV), 1011 Lausanne, Switzerland

e-mail: demartines@chuv.ch

D. Roulin

e-mail: didier.roulin@chuv.ch

C. Blanc

Department of Anesthesiology, University Hospital of Lausanne

(CHUV), 1011 Lausanne, Switzerland resections, respectively. Overall, 18 urgent patients (64\%) and 32 elective patients $(51 \%)$ developed postoperative complications $(p=0.261)$. Median postoperative length of stay was 8 days in the urgent setting compared with 5 days in the elective setting $(p=0.006)$.

Conclusions Many of the intra-operative and post-operative enhanced recovery items can also be applied to urgent colectomy, entailing outcomes that approach the results achieved in the elective setting.

\section{Introduction}

The use of enhanced recovery protocols in colorectal surgery allows a significant reduction of postoperative complications, hospital stay, and costs. At least in elective colorectal surgery, enhanced recovery pathways are nowadays considered by many as standard of care [1-5]. The recently updated Enhanced Recovery After Surgery (ERAS ${ }^{\circledR}$ ) guidelines provide a comprehensive overview of evidence-based measures for colonic surgery [6]. Compliance with those items is significantly related to improved clinical outcome and reduced complications following colorectal surgery [7].

The setting of urgent surgery obviously limits compliance with the entire protocol, as this was initially designed for elective surgery. Moreover, some patients operated on in urgency might be considered at higher risk. To the best of our knowledge, to date, no publication about enhanced recovery in the urgent setting has been reported. However, the potential benefits of those evidence-based protocols should not be denied to patients undergoing urgent surgery; therefore, we extended the application of enhanced recovery to urgent colectomy.

The objective of this prospective cohort study was to assess the feasibility of an enhanced recovery concept for urgent colonic surgery, and to compare elective and urgent 


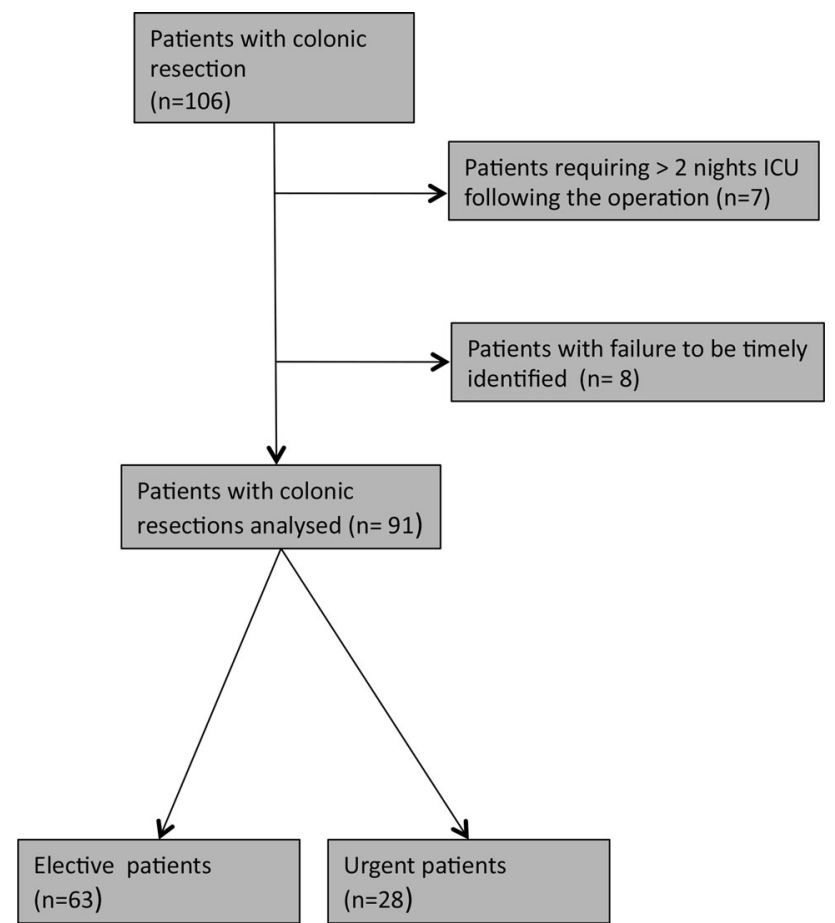

Fig. 1 Flow chart of patients with colonic resection from the 1st April 2012 to the 31st March 2013. ICU intensive care unit

procedures with regards to compliance with the enhanced recovery protocol and clinical outcome.

\section{Patients and methods}

In May 2011, a standardized enhanced recovery protocol for elective colon and rectum resections was implemented at the University Hospital of Lausanne [8]. From April 2012, all urgent colectomies were also systematically included in the same pathway. The present analysis was prospectively planned to monitor outcomes of urgent colonic resections within an established enhanced recovery pathway. Informed consent was obtained from all patients prior to surgery. The study was approved by the Institutional Review Board.

The study cohort consisted of all consecutive patients aged older than 18 years undergoing elective or urgent colon resection at our institution in a 1-year period from 1 April 2012 until 31 March 2013. Urgent colectomy was considered as any colonic resection performed during an unplanned hospital admission. All patients handled in the postoperative phase in our own unit were considered, including patients requiring high-dependency unit for continuous monitoring, non-invasive ventilation, or hemodynamic instability. Urgent patients requiring intensive care for at least 2 consecutive nights immediately after the index operation were not considered (Fig. 1). Patients having rectal resection were excluded from the present analysis.
Table 1 Enhanced recovery protocol for colonic surgery

Patient counselling Preadmission counselling and written information

\begin{tabular}{|c|c|}
\hline Bowel preparation & Avoidance of bowel preparation \\
\hline Fasting & Clear fluids until $2 \mathrm{~h}$, solids $6 \mathrm{~h}$ before surgery \\
\hline $\begin{array}{l}\text { Carbohydrate } \\
\text { drinks }\end{array}$ & $\begin{array}{l}800 \mathrm{ml} \text { on evening, and } 400 \mathrm{ml} 2 \mathrm{~h} \text { before } \\
\text { surgery }\end{array}$ \\
\hline Premedication & $\begin{array}{l}\text { No pre-operative long-acting sedative } \\
\text { premedication }\end{array}$ \\
\hline $\begin{array}{l}\text { Thrombo- } \\
\text { prophylaxis }\end{array}$ & LMW heparin $12 \mathrm{~h}$ before surgery, IPC \\
\hline $\begin{array}{l}\text { Antibiotic } \\
\text { prophylaxis }\end{array}$ & $\begin{array}{l}\text { Cefuroxime } 1.5 \mathrm{~g}+\text { metronidazole } 500 \mathrm{mg} \\
30 \mathrm{~min} \text { before incision }\end{array}$ \\
\hline $\begin{array}{l}\text { Postoperative } \\
\text { analgesia }\end{array}$ & $\begin{array}{l}\text { Thoracic epidural analgesia for laparotomy. } \\
\text { Epidural or PCA for laparoscopy }\end{array}$ \\
\hline $\begin{array}{l}\text { Hypothermia } \\
\text { prevention }\end{array}$ & Active warming (air blanket) \\
\hline PONV prophylaxis & $\begin{array}{l}\text { Droperidol } 1 \mathrm{mg} \text { at induction, ondansetron } \\
4 \mathrm{mg} \text { with or without betamethasone } 4 \mathrm{mg} \text { at } \\
\text { the end of operation }{ }^{\mathrm{a}}\end{array}$ \\
\hline $\begin{array}{l}\text { Balanced } \\
\text { intravenous } \\
\text { fluids }\end{array}$ & $\begin{array}{l}\text { Intraoperative crystalloids } 500-1,000 \mathrm{ml} \text { for } \\
\text { surgery }<3 \mathrm{~h} \text {, otherwise crystalloids } 1,500 \mathrm{ml} \text {, } \\
\text { colloids } 500-1,000 \mathrm{ml} \text {. Postoperative } \\
\text { crystalloids } 500 \mathrm{ml} \text { during the first } 24 \mathrm{~h} \text {, then } \\
\text { stop }\end{array}$ \\
\hline Nasogastric tubes & No routine postoperative nasogastric tube \\
\hline Abdominal drains & No routine abdominal drainage \\
\hline $\begin{array}{l}\text { Postoperative } \\
\text { analgesia }\end{array}$ & $\begin{array}{l}\text { Epidural or PCA removed after } 48 \mathrm{~h} \text {. } \\
\text { Paracetamol, ibuprofen, and oxycodone- } \\
\text { naloxone only for breakthrough pain }\end{array}$ \\
\hline Mobilisation & $\begin{array}{l}\text { Out of bed more than } 15 \text { min on day of surgery, } \\
\text { at least } 6 \mathrm{~h} \text { per day thereafter }\end{array}$ \\
\hline Nutrition & $\begin{array}{l}\text { Free fluid } 4 \mathrm{~h} \text { after surgery. Normal diet from } \\
\text { day of surgery. Two oral nutritional } \\
\text { supplements ( } 300 \mathrm{kcal} / \mathrm{unit}) \text { per day }\end{array}$ \\
\hline $\begin{array}{l}\text { Systematic } \\
\text { laxatives }\end{array}$ & Oral magnesium hydroxide \pm chewing gum \\
\hline Bladder catheter & Removal on postoperative day 1 \\
\hline Systematic audit & Systematic audit. Bi-monthly meeting \\
\hline
\end{tabular}

IPC intermittent pneumatic compression, $L M W$ low-molecular weight, $P C A$ patient-controlled analgesia, $P O N V$ postoperative nausea and vomiting

${ }^{a}$ Betamethasone only for women or non-smokers or those with previous history of PONV

All consecutive elective colonic resections were systematically managed within the established enhanced recovery protocol and were therefore chosen as reference for the urgent group. Prospective data collection and enhanced recovery protocol were identical for the two contemporary comparative groups.

Within the enhanced recovery protocol, pertinent demographic and surgical information was entered into the prospective database, the ERAS ${ }^{\circledR}$ Interactive Audit System, along with information on perioperative care items and clinical 
Fig. 2 Compliance with the enhanced recovery protocol by item in patients undergoing urgent compared to elective colectomy. Compliance to the enhanced recovery protocol by item in the pre-, intra- and postoperative phase for patients undergoing urgent (black) and elective colectomy (light grey), respectively. $*$ indicates statistical significance $(p<0.05) . E D A$ epidural anesthesia, $P O N V$ postoperative nausea and vomiting, ONS oral nutrition supplement, $P O D$ postoperative day

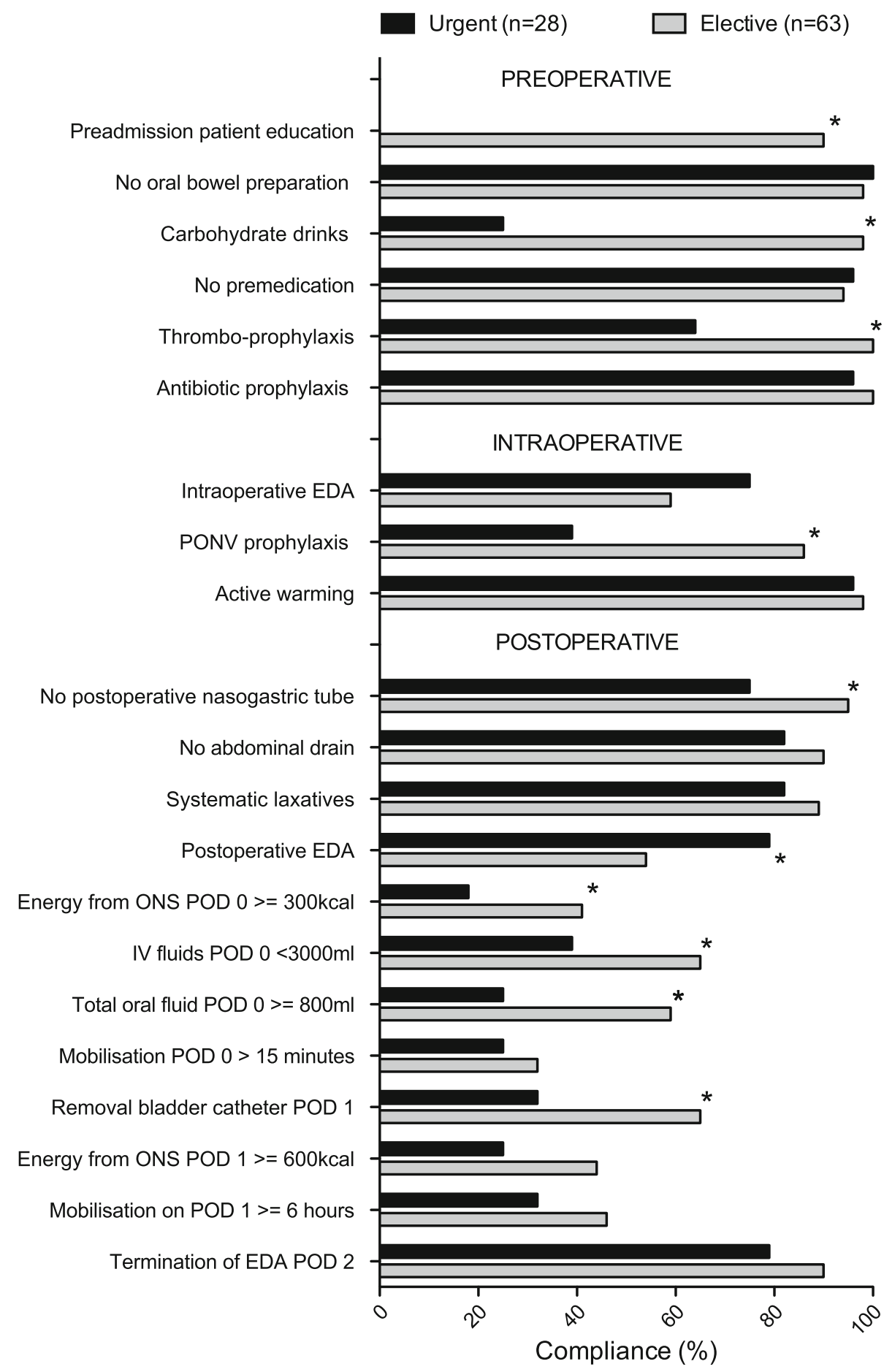

outcome. Data management was carried out by a dedicated and specially trained enhanced recovery nurse. All patients were followed for a minimum of 30 days after surgery.

Enhanced Recovery After Surgery pathway

The institutional enhanced recovery protocol (Table 1) adhered closely to current recommendations [6,9] and was recently published [8]. Sufficient postoperative pain control with oral analgesia, tolerance of solid food, and independent ambulation were mandatory discharge criteria, while passage of stool was only optional.

Outcome measures

The primary endpoint was compliance with the standardized enhanced recovery protocol in urgent colon surgery. Compliance was assessed as a dichotomous variable for 
every individual of the 21 enhanced recovery items as shown on Fig. 2. The percentages were calculated as compliant patients/total patients for urgent and elective groups, respectively. Overall compliance was calculated as number of fulfilled items divided by the total number of 21 items (\%); compliance of the three different phases was described accordingly using 6, 3, and 12 as the denominators for the pre-, intra-, and post-operative phase, respectively.

Secondary outcome measures included functional outcome, complications, and length of stay. Functional outcome was defined as return of bowel function (flatus/stool). Postoperative complications occurring within 30 postoperative days were graded on a 5-point severity scale according to Dindo et al. [10]. Complication grades IIIa to IVb were defined as severe complications. More than one complication per patient was possible, but only the highest ranked complication was used for final analysis. Furthermore, complications were divided into surgical and medical complications. Length of stay was counted from day of surgery until day of discharge. Total hospital stay included preoperative hospital days as well as readmission days within 30 days after surgery.

\section{Statistical analysis}

Descriptive statistics for categorical variables are reported as frequency $(\%)$, while continuous variables are reported as mean ( \pm standard deviation) or median (interquartile range) as appropriate. Continuous variables were compared between urgent and elective surgeries with the MannWhitney $U$ test or Student's $t$ test. Chi squared or Fisher's exact test were used for comparison of categorical variables. All statistical tests were two-sided, and a level of 0.05 was used to indicate statistical significance. Data analyses were performed using IBM SPSS ${ }^{\circledR}$ Statistic 20 (IBM, Armonk, NY, USA).

\section{Results}

Patients

During the 1-year study period, 28 patients underwent urgent colectomy and were managed within an enhanced recovery pathway. During the same time period, seven urgent patients stayed at least the 2 first nights after surgery in the intensive care unit for prolonged intubation and were thus not considered for enhanced recovery. Eight other patients had urgent colectomy in the study period but were not included in the enhanced recovery protocol due to neglect of the care team. Those patients were not accounted for in the urgent group, as they were not included in the
Table 2 Demographics and operation characteristics of patients undergoing urgent versus elective colectomy

\begin{tabular}{|c|c|c|c|}
\hline & $\begin{array}{l}\text { Urgent } \\
(N=28)\end{array}$ & $\begin{array}{l}\text { Elective } \\
(N=63)\end{array}$ & $p$ value \\
\hline Age (years) & $63.64 \pm 19.51$ & $61.41 \pm 17.94$ & $0.596^{\mathrm{a}}$ \\
\hline Sex ratio (M:F) & $12: 16$ & $36: 27$ & $0.264^{\mathrm{b}}$ \\
\hline $\begin{array}{l}\text { Body mass index } \\
\left(\mathrm{kg} / \mathrm{m}^{2}\right)\end{array}$ & $24.4 \pm 4.1$ & $26.6 \pm 4.2$ & $0.025^{\mathrm{a}}$ \\
\hline ASA grade & & & $0.002^{\mathrm{b}}$ \\
\hline I-II & $13(46)$ & $51(81)$ & \\
\hline III-IV & $15(54)$ & 12 (19) & \\
\hline \multicolumn{4}{|l|}{ P-POSSUM } \\
\hline Physiologic & $22 \pm 6$ & $19 \pm 6$ & $0.128^{\mathrm{a}}$ \\
\hline Operative & $15 \pm 4$ & $12 \pm 4$ & $<0.001^{\mathrm{a}}$ \\
\hline Diagnosis & & & $0.106^{\mathrm{c}}$ \\
\hline Neoplasia & $14(50)$ & $45(71)$ & \\
\hline Diverticular disease & $6(21)$ & $10(16)$ & \\
\hline Others & $8(29)$ & $8(13)$ & \\
\hline Surgical approach & & & $<0.001^{\mathrm{c}}$ \\
\hline Laparoscopic & $5(18)$ & $41(65)$ & \\
\hline Open & $22(79)$ & $13(21)$ & \\
\hline Converted & $1(3)$ & $9(14)$ & \\
\hline Procedure & & & $0.125^{\mathrm{c}}$ \\
\hline $\begin{array}{l}\text { Ileocaecal/right } \\
\text { hemicolectomy }\end{array}$ & $10(36)$ & $27(43)$ & \\
\hline $\begin{array}{l}\text { Left hemicolectomy/ } \\
\text { sigmoidectomy }\end{array}$ & $13(46)$ & $33(52)$ & \\
\hline Total colectomy & $5(18)$ & $3(5)$ & \\
\hline $\begin{array}{l}\text { Stoma (protective or } \\
\text { definitive) }\end{array}$ & $5(18)$ & $2(3)$ & $0.027^{\mathrm{b}}$ \\
\hline $\begin{array}{l}\text { Estimated blood loss } \\
\quad(\mathrm{ml})\end{array}$ & $344 \pm 302$ & $274 \pm 414$ & $0.470^{\mathrm{a}}$ \\
\hline Surgery duration (min) & $181 \pm 55$ & $208 \pm 86$ & $0.147^{\mathrm{a}}$ \\
\hline
\end{tabular}

Values are presented as mean $\pm \mathrm{SD}$ or $N(\%)$ unless otherwise indicated

ASA American Society of Anesthesiologists, $F$ female, $M$ male, $P$ POSSUM Portsmouth Physiological and Operative Severity Score for the enumeration of Mortality and morbidity [11], $S D$ standard deviation

a Unpaired $t$ test

b Fisher's exact test

${ }^{\mathrm{c}}$ Chi squared test

protocol (Fig. 1). Reasons for urgent colectomies were mechanical bowel obstruction $(N=13)$, hematochezia $(N=6)$, and perforation $(N=9)$. One patient was operated within $2 \mathrm{~h}$ following admission, nine were operated 2-24 $\mathrm{h}$ after admission, and the 18 remaining patients were operated more than $24 \mathrm{~h}$ after an unplanned admission. In the same period, 63 patients were operated electively. Demographic information for the two comparative groups is presented along with pertinent surgical details in Table 2. Considerable differences between elective and 
urgent patients included a significantly increased American Society of Anesthesiologists (ASA) and P-POSSUM (Portsmouth physiologic and operative severity score for the enumeration of mortality and morbidity) operative score [11]; urgent procedures were more frequently performed as open surgeries. More urgent $(75 \%)$ than elective (29\%) patients needed to stay in the high-dependency unit $(p=0.012)$. Furthermore, urgent patients had a significantly longer length of stay in the high-dependency unit (median 3 days; interquartile range 3-6) than elective colectomy patients (median 1 day; interquartile range 0-2) $(p<0.001)$.

Compliance with the enhanced recovery protocol

Overall compliance of urgent patients with the standardized enhanced recovery protocol was $57 \%$. Preoperative measures were applied with $64 \%$ compliance, while intraand postoperative measures were followed with 77 and $49 \%$, respectively. Details on individual items are displayed in Fig. 2. Problematic items in urgent compared with elective patients were preadmission patient education (0\%), preoperative carbohydrate drinks (25\%), prophylactic anti-emetic medication (39\%), oral nutritional supplements more than $300 \mathrm{kcal}$ on day of surgery $(18 \%)$, oral fluids on day of surgery $(25 \%)$, balanced intravenous fluids on day of surgery (39\%), and removal of urinary catheter postoperative day $1(32 \%)$. For the comparative group of elective patients, overall compliance with the enhanced recovery protocol was $77 \%$. Preoperative measures were applied with $96 \%$ compliance, while intra- and postoperative measures were followed with 86 and $67 \%$ compliance, respectively.

Of note, avoidance of oral bowel preparation, of longacting premedication, and of abdominal drains, as well as the use of antibiotic prophylaxis, upper body forced-air heating cover, and laxative had the same high compliance rates in both urgent and elective cases.

Functional recovery, complications, length of stay

Postoperative outcomes are detailed in Table 3. On average, urgent patients passed flatus after 3 days and passed stools after 3 days compared with $2(p=0.006)$ and 3 days ( $p=0.153$ ) for elective patients, respectively. Overall, 18 urgent patients $(64 \%)$ and 32 elective patients $(51 \%)$ developed postoperative complications ( $p=0.261)$. There was a similar rate of minor complications between urgent (36\%) and elective patients $(38 \%)(p=0.477)$, while 6 of 28 urgent patients $(21 \%)$ and 7 of 63 elective patients (11\%) experienced major complications $(p=0.209)$. The total numbers of surgical and medical complications are provided in Table 4 . There were statistically more
Table 3 Clinical outcomes of patients undergoing urgent versus elective colectomy

\begin{tabular}{llll}
\hline Outcome & $\begin{array}{l}\text { Urgent } \\
(N=28)\end{array}$ & $\begin{array}{l}\text { Elective } \\
(N=63)\end{array}$ & $p$ value \\
\hline First passage of flatus (POD) & $3(2-4)$ & $2(1-3)$ & $0.006^{\mathrm{a}}$ \\
First passage of stool (POD) & $3(3-5)$ & $3(2-4)$ & $0.153^{\mathrm{a}}$ \\
Postoperative stay (days) & $8(5-15)$ & $5(4-9)$ & $0.006^{\mathrm{a}}$ \\
Total hospital stay (days) & $16(8-32)$ & $6(5-13)$ & $<0.001^{\mathrm{a}}$ \\
Patients with a complication & & & \\
$\quad$ within 30 POD & $10(36)$ & $24(38)$ & $0.477^{\mathrm{b}}$ \\
Grade I-II & $6(21)$ & $7(11)$ & $0.209^{\mathrm{b}}$ \\
Grade IIIa-IVb & $2(7)$ & $1(2)$ & $0.223^{\mathrm{b}}$ \\
$\quad$ Grade V & $1(4)$ & $1(2)$ & $0.523^{\mathrm{b}}$ \\
Readmission within 30 POD & &
\end{tabular}

Values are presented as median (interquartile range) or $N(\%)$ unless otherwise indicated

$P O D$ postoperative days

a Mann-Whitney $U$ test

${ }^{b}$ Fisher's exact test

Table 4 Type of complications within 30 days after surgery

\begin{tabular}{|c|c|c|c|}
\hline & $\begin{array}{l}\text { Urgent } \\
(N=28)\end{array}$ & $\begin{array}{l}\text { Elective } \\
(N=63)\end{array}$ & $p$ value $^{\mathrm{a}}$ \\
\hline $\begin{array}{l}\text { Total number of surgical } \\
\text { complications }\end{array}$ & 23 & 22 & \\
\hline Postoperative ileus & $6(21)$ & $7(11)$ & 0.209 \\
\hline $\begin{array}{l}\text { Anastomotic leak/intra- } \\
\text { abdominal abscess }\end{array}$ & $3(11)$ & $3(5)$ & 0.367 \\
\hline $\begin{array}{l}\text { Mechanical bowel } \\
\text { obstruction }\end{array}$ & $1(4)$ & 0 & 0.308 \\
\hline Wound infection & $7(30)$ & $6(10)$ & 0.100 \\
\hline Postoperative bleeding & $1(4)$ & $1(2)$ & 0.523 \\
\hline Abdominal wall dehiscence & $2(7)$ & 0 & 0.092 \\
\hline Urinary tract injury & $1(4)$ & $2(3)$ & 1.000 \\
\hline $\begin{array}{l}\text { Peridural-related } \\
\text { complications }\end{array}$ & $2(7)$ & $3(5)$ & 0.641 \\
\hline $\begin{array}{l}\text { Total number of medical } \\
\text { complications }\end{array}$ & 19 & 21 & \\
\hline $\begin{array}{l}\text { Cardiac arrhythmia/acute } \\
\text { myocardial infarction }\end{array}$ & $5(18)$ & $1(2)$ & 0.010 \\
\hline Acute renal failure & 0 & $2(3)$ & 1.000 \\
\hline $\begin{array}{l}\text { Deep venous thrombosis/ } \\
\text { pulmonary embolism }\end{array}$ & $2(7)$ & 0 & 0.092 \\
\hline Lobar atelectasis/pleural fluid & $2(7)$ & 0 & 0.092 \\
\hline Pneumonia & $5(18)$ & $2(3)$ & 0.027 \\
\hline Urinary tract infection & $2(7)$ & $4(6)$ & 1.000 \\
\hline Urinary retention & $3(11)$ & 12 (19) & 0.378 \\
\hline
\end{tabular}

${ }^{a}$ Fisher's exact test

cardiovascular events $(p=0.010)$ and pneumonias $(p=0.027)$ in the urgent group. Median postoperative length of stay was 8 days in the urgent setting compared with 
5 days in elective cases $(p=0.006)$. One urgent and one elective patient were readmitted within 30 days after surgery, with total readmission stays of 5 and 8 days, respectively.

\section{Discussion}

Application of an enhanced recovery pathway for urgent colectomy is feasible and beneficial. Many of the recommended measures can be applied in the urgent situation similarly to an elective setting.

The evaluation of compliance is essential in a study focusing on enhanced recovery $[7,12]$. Comparisons with other studies are difficult for two main reasons: enhanced recovery protocols differ considerably among institutions and the actual application of the intended protocol is rarely reported. The number of enhanced recovery items reported in prospective studies varied from 4 to 14 in two different systematic reviews [3, 13]. However, actual compliance was not reported in any of those studies and therefore remains unknown. Our institutional enhanced recovery protocol adheres closely to the recently updated ERAS ${ }^{\circledR}$ guidelines, which summarize comprehensively and in detail the best available perioperative care [6]. The recommended 21 items were prospectively monitored to assess protocol compliance.

The high compliance achieved in the present study in the pre- and intra-operative phases for elective patients was comparable or even higher when compared with previous studies [7, 12-16]. Only the use of epidural analgesia, with a compliance of about $50 \%$, was lower in our study, because of an ongoing randomized controlled trial comparing epidural with patient-controlled analgesia for laparoscopic colorectal surgery (clinicaltrials.gov: NCT00508300). Compared with the elective setting, pre-operative compliance for urgent patients was significantly lower. This is no surprise, as preadmission patient counseling was not possible in the urgent setting. Furthermore, the administration of preoperative carbohydrate drinks could not be anticipated because of the timing of the operation; nor could it be administered to patients with mechanical bowel obstruction. Among the intraoperative items, only the prophylaxis of postoperative nausea and vomiting was significantly lower in the urgent group. This difference was due to the fact that urgent procedures were usually not managed by enhanced recovery-trained anesthetists working in visceral surgery. This latter item is a good example for potential future improvements in our institution, while previously mentioned measures are limitations inherent to the urgency situation.

Concerning post-operative compliance, items like avoidance of abdominal drain, routine use of laxative, and removal of epidural on postoperative day 2 achieved a high compliance of between 80 and $90 \%$ in both the elective and the urgent setting. This was due to a general no-drain policy, and the use of standardized clinical pathways. Only removal of nasogastric tube before extubation was routinely performed in the elective group, but significantly less often in the urgent group, which included a certain number of patients with preoperative intestinal occlusion. It remains to be evaluated whether routine nasogastric drainage can be safely omitted in this situation. As already shown in previous studies on elective enhanced recovery colorectal surgery, the most challenging items in the postoperative period were early enteral drinking and feeding as well as early mobilization $[12,13]$. This was even more accentuated in the urgent cases, as observed in our present study. Of note, this difference decreased with the number of postoperative days. There was a significantly lower compliance with oral fluids, nutritional supplements, and mobilization on the day of surgery in urgent compared with elective, but the difference was no longer significant on postoperative day 1 .

Functional outcome was similar between elective and urgent colectomy, with a median of first bowel motion occurring after 3 postoperative days, which is comparable to previous series of colonic resection within an enhanced recovery protocol [14] and is probably physiologic. The overall complication rate was in the range of 24-54\% described in the current literature for elective colorectal resection within an enhanced recovery protocol $[3,5,7,14$, 17]. The variation of the complication rates depends on the definition and the type of complications reported and on the completeness and quality of post-surgical audit. In the present study, all type of complications-medical and surgical, minor and major-were prospectively collected by a dedicated enhanced recovery nurse until 30 days after surgery. Despite a trend toward more major complications in urgent compared with elective procedures, there was no statistical difference. Whilst the latter may be due to the small numbers of patients in the study, the use of an enhanced recovery protocol in urgent patients did not appear to result in increased overall complication rates. Moreover, urgent patients had higher ASA and P-POSSUM scores and underwent more open procedures and ostomy creations; these are acknowledged risk factors for postoperative morbidity and prolonged hospital stay and hence disadvantage the urgent group compared with the elective group. Nonetheless, a median length of stay of 8 days observed in our urgent group (with more than $80 \%$ open procedures), is similar to previously described lengths of stay in open elective colectomy with standard care [14, 18]. Furthermore, an historical cohort of elective colectomy patients from our institution prior to implementation of an enhanced recovery protocol had outcomes that were very similar to those of our urgent cohort; the first flatus took place at median day 3 $(p=0.303)$ and the median hospital stay was 8 days 
( $p=0.775$ ) [8]. Our reported readmission rate of $4 \%$ for urgent patients is acceptable, and lies in the range between 0 and $9.7 \%$ readmission rate described after elective colorectal surgery within enhanced recovery program [19].

Several limitations of the present study need to be addressed. Patients undergoing elective and urgent colectomy showed obvious differences in terms of demographics, surgical details, and outcome. Our study population therefore represented non-matched comparative groups in favor of the elective group. In our view, this comparison is still useful. A reference is needed to assess which elective enhanced recovery items are applicable in the urgent setting compared with elective conditions. The study design did not intend to analyze clinical benefits of an enhanced recovery protocol for urgent colectomy. A prospective analysis seemed more appropriate to improve further current practice. A randomized trial comparing enhanced recovery versus traditional care for urgent colectomy would raise ethical issues in view of the overwhelming evidence of enhanced recovery pathways for elective procedures.

During the study period, there were some 15 urgent patients who could not be included in the enhanced recovery protocol. Some stayed for more than 2 nights in the intensive care unit, where the application of an enhanced recovery protocol was not feasible, as most of these patients were intubated. Some other patients were not identified by the enhanced recovery team for logistical reasons as most were operated on over the weekend. This is an important logistic challenge that we currently try to overcome via continuous education measures. Our cohort study is limited and larger-scale prospective observational studies and registries should help to identify pitfalls in the current enhanced recovery protocol. This could lead to the development of a modified and dedicated enhanced recovery protocol for urgent procedures.

In summary, many of the enhanced recovery items can be applied for urgent colectomy, and no significant adverse effect was observed despite higher ASA and P-POSSUM scores and more stressful procedures in urgent patients. Enhanced recovery protocols can therefore be considered for patients undergoing urgent colectomy.

Acknowledgments The authors would like to acknowledge the support provided by all members of the enhanced recovery team in Lausanne, especially V. Addor, our enhanced recovery-dedicated Clinical Nurse.

Disclosure Grant support and conflict of interest: none.

\section{References}

1. Rawlinson A, Kang P, Evans J, Khanna A (2011) A systematic review of enhanced recovery protocols in colorectal surgery. Ann R Coll Surg Engl 93:583-588
2. Wind J, Polle SW, Fung Kon Jin PH et al (2006) Systematic review of enhanced recovery programmes in colonic surgery. $\mathrm{Br} \mathrm{J}$ Surg 93:800-809

3. Varadhan KK, Neal KR, Dejong CH et al (2010) The Enhanced Recovery After Surgery (ERAS) pathway for patients undergoing major elective open colorectal surgery: a meta-analysis of randomized controlled trials. Clin Nutr 2010:434-440

4. Kehlet H (2011) Surgery: fast-track colonic surgery and the 'knowing-doing' gap. Nat Rev Gastroenterol Hepatol 8:539-540

5. Spanjersberg WR, Reurings J, Keus F, van Laarhoven CJ (2011) Fast track surgery versus conventional recovery strategies for colorectal surgery. Cochrane Database Syst Rev (2):CD007635

6. Gustafsson UO, Scott MJ, Schwenk W et al (2013) Guidelines for perioperative care in elective colonic surgery: enhanced Recovery After Surgery $\left(\right.$ ERAS $\left.^{\circledR}\right)$ Society recommendations. World J Surg 37:259-284. doi:10.1007/s00268-012-1772-0

7. Gustafsson UO, Hausel J, Thorell A et al (2011) Adherence to the Enhanced Recovery After Surgery protocol and outcomes after colorectal cancer surgery. Arch Surg 146:571-577

8. Roulin D, Donadini A, Gander S et al (2013) Cost-effectiveness of the implementation of an enhanced recovery protocol for colorectal surgery. Br J Surg 100:1108-1114

9. Lassen K, Soop M, Nygren J et al (2009) Consensus review of optimal perioperative care in colorectal surgery: enhanced Recovery After Surgery (ERAS) Group recommendations. Arch Surg 144:961-969

10. Dindo D, Demartines N, Clavien PA (2004) Classification of surgical complications: a new proposal with evaluation in a cohort of 6336 patients and results of a survey. Ann Surg 240:205-213

11. Prytherch DR, Whiteley MS, Higgins B et al (1998) POSSUM and Portsmouth POSSUM for predicting mortality. Physiological and Operative Severity Score for the enUmeration of Mortality and morbidity. Br J Surg 85:1217-1220

12. Maessen J, Dejong CH, Hausel J et al (2007) A protocol is not enough to implement an enhanced recovery programme for colorectal resection. Br J Surg 94:224-231

13. Ahmed J, Khan S, Lim M et al (2012) Enhanced Recovery After Surgery protocols - compliance and variations in practice during routine colorectal surgery. Colorectal Dis 14:1045-1051

14. Vlug MS, Wind J, Hollmann MW et al (2011) Laparoscopy in combination with fast track multimodal management is the best perioperative strategy in patients undergoing colonic surgery: a randomized clinical trial (LAFA-study). Ann Surg 254:868-875

15. Gillissen F, Hoff C, Maessen JM et al (2013) Structured synchronous implementation of an enhanced recovery program in elective colonic surgery in 33 hospitals in the Netherlands. World J Surg 37:1082-1093. doi:10.1007/s00268-013-1938-4

16. Cakir H, van Stijn MF, Lopes Cardozo AM et al (2013) Adherence to Enhanced Recovery After Surgery (ERAS) and length of stay after colonic resection. Colorectal Dis 15:1019-1025

17. Sammour T, Zargar-Shoshtari K, Bhat A et al (2010) A programme of Enhanced Recovery After Surgery (ERAS) is a costeffective intervention in elective colonic surgery. $\mathrm{N} \mathrm{Z} \mathrm{Med} \mathrm{J}$ 123:61-70

18. Muller S, Zalunardo MP, Hubner M et al (2009) A fast-track program reduces complications and length of hospital stay after open colonic surgery. Gastroenterology 136:842-847

19. Adamina M, Kehlet H, Tomlinson GA et al (2011) Enhanced recovery pathways optimize health outcomes and resource utilization: a meta-analysis of randomized controlled trials in colorectal surgery. Surgery 149:830-840 